\title{
Adesão ao trabalho do Personal Trainer
}

\author{
Personal Trainer adhesion to work
}

\author{
Adhesión al trabajo del Entrenador Personal
}

\author{
Juliana Neves Pereira da Silva ${ }^{I}$, Larissa Castro Lima ${ }^{\text {II }}$, Carlos Alberto de Andrade Coelho Filho ${ }^{\text {III }}$
}

\begin{abstract}
Resumo
Esta pesquisa, de natureza qualitativa, objetiva captar elementos associados à adesão ao trabalho do personal trainer. Doze clientes de uma academia de ginástica foram entrevistados. Princípios da entrevista compreensiva nortearam os procedimentos de coleta, análise e interpretação de dados. Concluímos que é importante o personal olhar para o seu cliente e não enxergar apenas um organismo, bem como ter cuidado para não deixar transparecer sentimentos desagradáveis durante o trabalho. Há cobrança por um profissional que esteja sempre ao lado do cliente, que não faça uso do celular durante as sessões de treinamento que orienta, que seja flexível e pontual.
\end{abstract}

Palavras-chave: Personal Trainer; Adesão; Capacitação Profissional

\begin{abstract}
This research, of a qualitative nature, aims to capture elements associated to the Personal Trainer adhesion to work. Twelve clients of a gym were interviewed. Principles of the comprehensive interview guided the procedures of data collection, analysis and interpretation. We conclude that it is important for the personal trainer to look at his/her it is important to client and not only see an organism, as well as be careful not to show unpleasant feelings during work. There is a demand for a professional who is always next to the client, who does not use the cell phone during the training sessions that he/she guides, a Personal Trainer that is flexible and punctual.
\end{abstract}

Keywords: Personal Trainer; Adhesion; Professional Training

${ }^{\text {I } U n i v e r s i d a d e ~ F e d e r a l ~ d e ~ J u i z ~ d e ~ F o r a ~-~ U F J F ~-~ J u i z ~ d e ~ F o r a, ~ M G, ~ B r a s i l ~-~ A v e n i d a ~ D o u t o r ~ P a u l o ~ J a p i a s s u ~ C o e l h o, ~ 209 / 802, ~ C a s c a t i n h a, ~ J u i z ~ d e ~ F o r a, ~ M G, ~ B r a s i l ~}$ - CEP 36033-310 - e-mail: juneves94@ hotmail.com

II Universidade Federal de Juiz de Fora - UFJF- Juiz de Fora, MG, Brasil - e-mail: larissajf19@ yahoo.com.br

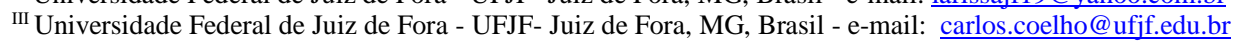




\section{Resumen}

Esta investigación, de naturaleza cualitativa, tiene como objetivo captar elementos asociados a la adhesión al trabajo del Entrenador Personal. Se entrevistó a doce clientes de un gimnasio. Los principios de la entrevista comprensiva orientaron los procedimientos de recolección, análisis e interpretación de datos. Concluimos que es importante que el entrenador mire a su cliente y no vea sólo un organismo, así como tenga cuidado de no dejar pasar sentimientos desagradables durante el trabajo. Hay demanda por un profesional que esté siempre al lado del cliente, que no haga uso del teléfono móvil durante las sesiones de entrenamiento que orienta, que sea flexible y puntual.

Palavras clave: Entrenador Personal; Adhesión; Capacitación Profesional

\section{Introdução}

Associado à procura pela melhora ou manutenção das capacidades físicas, ao alcance de resultados estéticos e ao interesse por certo acompanhamento mais eficaz e seguro durante a prática de exercícios físicos, segundo Prado e Liberal (2008), constata-se uma tendência à utilização dos serviços de treinamento personalizado.

Sanches (2006) define o personal trainer como um profissional graduado em Educação Física que formula e executa programas individualizados de treinamento vinculados à prática de exercícios físicos. O personal trainer atua em diversos espaços, tais como academias, residências, parques ou praças, clubes e condomínios, entre outros.

Pinheiro (2000) observa que o trabalho como personal trainer tornou-se cobiçado, graças ao nível de remuneração alcançado e ao sentimento de realização que possibilita. Para esse autor, diante da oportunidade de ascensão profissional, o personal trainer começou a investir em si mesmo, procurando cursos de pós-graduação e inovação no mercado. Mas, ainda, deve-se considerar que a maximização do investimento de energia pessoal para atuar nesse tipo de atividade profissional pode estar relacionada ao aumento gradativo do número de graduados em Educação Física no nosso país, conforme verifica Proni (2010).

Livros técnicos e manuais são produzidos e oferecem suporte para profissionais de Educação Física que desejam trabalhar na área de treinamento personalizado. No interior desse material, além de estratégias relacionadas à montagem de programas de exercícios físicos, sobressaem e são recorrentes palavras como cliente, concorrência, negociação, marketing, credibilidade, serviço, propaganda, consumidor, produto, mercado e parcerias. São palavras que se presentificam em discursos que parecem assumir o lugar de orientar, indicando os caminhos de como se tornar um personal de sucesso, sugerindo estratégias de 
marketing pessoal e contratuais vinculadas à crescente concorrência estabelecida no mercado da prática de exercícios físicos (BOSSLE, 2008).

O personal trainer deve, portanto, nesse diapasão, proporcionar um serviço de qualidade e fidelizar seus clientes, mas também encontrar soluções para contornar os períodos de baixa procura. Segundo Anversa e Oliveira (2011), uma característica marcante desse mercado é a instabilidade relacionada à variação na demanda durante os períodos de inverno e férias escolares, contrapondo-se ao incremento da procura verificado com a chegada do verão e nos meses que antecedem as férias de final de ano.

Dentre os motivos que levam pessoas a aderir ao treinamento personalizado, Sombrio (2011) destaca a competência do profissional associada ao alcance dos resultados esperados, bem como a motivação pessoal demonstrada pelo personal trainer com a realização do seu trabalho, transparecendo um público exigente e necessitado de incentivo para a prática do exercício físico. Esse autor sugere a realização de pesquisas qualitativas sobre a temática da motivação de clientes para a procura pelo treinamento personalizado, isto é, estudos que possam evidenciar representações de usuários acerca das características profissionais de personal trainer que buscam, bem como das motivações pessoais para a realização do treinamento personalizado com a orientação de profissionais de Educação Física.

Bossle e Fraga (2011), apresentando um mapeamento das referências dedicadas à formação do personal trainer, destacam a baixa produção científica sobre o assunto. Considerando, portanto, o interesse pelo trabalho como personal trainer e a carência de estudos sobre a temática, o objetivo desta pesquisa é captar elementos associados à adesão ao trabalho do personal trainer, especialmente, a produção do discurso que acompanha a busca pelos serviços de personal trainer.

\section{Método}

Esta pesquisa é de natureza qualitativa. A tradição hermenêutica das abordagens qualitativas parte do pressuposto de que as pessoas agem em função de suas crenças, percepções, sentimentos e valores, e que seus comportamentos seguem a ordenação de um sentido, que não se dá a conhecer de modo imediato, necessitando ser desvelado (ALVES-MAZZOTTI, 1991).

O projeto foi aprovado pelo Comitê de Ética em Pesquisa Humana da Universidade Federal de Juiz de Fora (parecer $\left.n^{\circ} 1.698 .199\right)$. 


\section{Participantes}

Esta pesquisa contou com a participação de doze clientes de uma academia situada na cidade de Juiz de Fora, Minas Gerais. A academia foi selecionada por ter perfil empresarial consolidado e por permitir o acesso para a realização da pesquisa.

Para a seleção dos participantes, utilizamos os seguintes critérios de inclusão: ser pessoa adulta; praticar exercícios físicos com orientação de personal trainer; prontificar-se a participar, livremente, da pesquisa (assinando o Termo de Consentimento Livre e Esclarecido).

Quadro 1 - Caracterização do grupo participante

\begin{tabular}{|c|c|c|c|c|c|}
\hline Entrevistada/o & Sexo & Idade & $\mathbf{X}$ & $\mathbf{Y}$ & $\mathbf{Z}$ \\
\hline E1 & $\mathrm{F}$ & 18 & 6 Anos & 1 mês & 3 vezes \\
\hline E2 & M & 49 & 17 anos & 1 mês & 2 vezes \\
\hline E3 & $\mathrm{F}$ & 30 & 16 anos & 1 ano e 10 meses & 2 vezes \\
\hline E4 & M & 38 & 28 anos & 8 anos & 5 vezes \\
\hline E5 & $\mathrm{F}$ & 53 & 1 ano e 7 meses & 1 ano e 7 meses & 2 vezes \\
\hline E6 & $\mathrm{F}$ & 34 & 13 anos & 5 anos & 2 vezes \\
\hline E7 & $\mathrm{F}$ & 38 & 15 anos & 2 anos e 6 meses & 3 vezes \\
\hline E8 & $\mathrm{F}$ & 39 & 15 anos & 11 anos & 3 vezes \\
\hline E9 & $\mathrm{F}$ & 39 & 1 ano & 1 ano & 2 vezes \\
\hline E10 & $\mathrm{F}$ & 33 & 7 anos & 4 anos & 3 vezes \\
\hline E11 & $\mathrm{F}$ & 53 & 10 anos & 1 ano & 3 vezes \\
\hline E12 & M & 28 & 2 anos & 6 meses & 3 vezes \\
\hline
\end{tabular}

X: Há quanto tempo pratica exercícios físicos.

Y: Há quanto tempo pratica exercícios físicos com orientação de personal trainer.

Z: Regularidade semanal da prática de exercícios físicos com orientação de personal trainer.

Fonte: Quadro elaborado pelos autores.

\section{Instrumento}

O instrumento utilizado para a coleta de dados foi a entrevista. O roteiro de questões que norteou as reflexões durante as entrevistas é o seguinte: Idade? Há quanto tempo você pratica exercícios físicos? Há quanto tempo você pratica exercícios físicos com orientação de personal trainer? Qual a regularidade dessa prática? Quais as cláusulas do contrato estabelecido entre você e a/o personal trainer? Porque buscou a orientação de um/a personal trainer? O que espera da/o personal trainer? O que não espera da/o personal 
trainer? O que pode destacar como característica positiva e/ou negativa da/o sua/seu personal? Qual o diferencial de um programa personalizado de exercícios físicos para você?

\section{Procedimentos}

As entrevistas, conduzidas pelos próprios pesquisadores, foram registradas em um minigravador e ocorreram em dia, horário e local de maior conveniência para os participantes. A coleta de dados foi interrompida mediante a consideração de que as informações captadas atingiram um "ponto de redundância” (ALVES-MAZZOTTI, 1991), isto é, estavam suficientemente confirmadas e com poucas possibilidades de emergirem novas informações relevantes que justificassem a continuidade da coleta.

Princípios da "entrevista compreensiva" (KAUFMANN, 2013) nortearam os procedimentos de coleta, análise e interpretação de dados (encerrados no mês de julho de 2018). Desses princípios, destaquese a busca por um tom, durante a realização das entrevistas, muito mais próximo de uma conversa entre iguais (no sentido de se trocar ideias em torno do tema com os entrevistados) do que aquele do questionário administrado de cima para baixo. Considere-se ainda a importância, na entrevista compreensiva, de que o pesquisador esteja ativamente envolvido nas questões, para provocar o envolvimento do entrevistado. Kaufmann (2013) observa que

\footnotetext{
a condução de entrevistas, ainda que seja um momento excepcional e muito difícil de ser realizado perfeitamente, não constituiu a fase mais importante da pesquisa. Esta vem em seguida, com a análise do material, segunda parte da investigação, verdadeiro ponto de partida do trabalho de aprofundamento, e que pode recuperar largamente as fraquezas da fase precedente (KAUFMANN, 2013, p. 118).
}

Quanto ao processo analítico, registre-se a importância de o pesquisador se deixar surpreender pelo material coletado e valorizar as articulações entre os diferentes níveis de reflexão por ele proporcionados. A título de exemplo, escutando sucessivas vezes as gravações, por compreender que em singular investida aos dados empíricos elementos novos lhe tocarão, aspectos não antes percebidos emergirão e proporcionarão pensamentos até então inusitados. Mais ainda, nesta dinâmica, não se pode perder de vista a indispensabilidade em "correr o risco da interpretação" (KAUFMANN, 2013, p. 146), pois não há pesquisa possível sem ela.

Ressalte-se também que o resultado não depende do conteúdo, simples matéria-prima, mas da capacidade analítica do pesquisador. Como acentua Kaufmann (2013), é preciso fazer os fatos falarem, encontrar indícios, se interrogar a respeito da mínima frase. 


\section{Análise e interpretação das informações}

Um elemento que pode fortalecer a relação entre profissionais e clientes de personal, no sentido de influenciar a motivação ${ }^{1}$ dos últimos, é o fornecimento adequado de feedback por parte dos profissionais. Tertuliano et al.(2008), por exemplo, indicam existir certo consenso entre pesquisadores da área da aprendizagem motora de que a prática e o feedback extrínseco são fatores essenciais para a aprendizagem de habilidades motoras. Coelho Filho (2014), considerando o problema da motivação para a prática regular de atividades físico-esportivas, sublinha que quando a pessoa é reconhecida por suas capacidades e realizações o seu sentimento de autoestima aumenta. Trata-se, portanto, de constructos teóricos que podem subsidiar alguma compreensão vinculada à adesão ao trabalho do personal trainer. Vejamos o que diz a entrevistada: “(O profissional) não deixa eu desistir. Às vezes eu estou na esteira querendo parar e ele não me deixa desistir: 'Só falta um minuto; falta dois'. Isso vai te motivando a não parar” (E8).

Segundo Silva e Araújo Silva (2009), o acompanhamento com personal trainer, em comparação ao acompanhamento padrão em academia de ginástica, torna o treinamento mais intenso, com redução do tempo total da sessão, maior esforço e consequentemente maior gasto energético. A entrevistada elabora: "O corpo responde de outra maneira. Impressionante! E o personal estando ali, te dando aquele apoio, te mandando para cima, te dando força e tal, motivação, é outra coisa" (E6). Verifica-se, então, a cobrança por um profissional que esteja sempre ao lado do cliente, que contribua para que ele tenha vontade de ir à academia, que ofereça motivos para que ele faça as atividades com afinco. Trata-se de aspectos que foram muito observados nas entrevistas.

Além disso, a importância da atenção relacionada à execução dos exercícios emergiu de forma recorrente: "(Sem o personal trainer) eu tinha a sensação de que fazia vários exercícios errados, e como a academia tem muita gente, às vezes o instrutor não tem a capacidade de olhar para você separado" (E1).

Como podemos verificar, ao mesmo tempo em que os entrevistados enaltecem o trabalho do personal por conta do apoio, do incentivo, do acompanhamento durante a execução dos exercícios, emerge uma crítica (explícita ou mesmo velada) à orientação que é dispensada por profissionais de Educação Física a clientes em academias de ginástica:

Eu trabalho tanto que eu posso fazer um investimento em mim. Para mim é um investimento; na minha saúde, na minha postura. Que eu não sinto dor de coluna, não sinto nada. E antes de ter personal, eu malhava em outra academia, eu vivia com a coluna estourada. Por quê? É exercício

\footnotetext{
${ }^{1}$ A palavra motivação se situa nesta pesquisa estritamente associada à sua ocorrência nos trabalhos consultados e no material empírico coletado. Trata-se de um cenário discursivo que remete para certa concepção de motivação, qual seja, de que ela conduz a pessoa a realizar algo, a se envolver em alguma atividade, ou mesmo a não realizar e a não se envolver. Nesse sentido, sublinhe-se que a motivação está intrinsecamente relacionada à adesão. Motivado a fazer = adesão. Motivado a não fazer (desmotivado) = não adesão.
} 
errado, é postura errada. Hoje não, acabou esse problema. Então eu estou investindo em mim. É caro? É caro, não é qualquer pessoa que pode fazer com personal. (E11).

Com base na análise das entrevistas, fica evidente que o personal trainer deve ter sensibilidade para perceber as necessidades das pessoas que orienta (clientes), especialmente, dando-lhes incentivo na medida certa. É interessante registrar como as necessidades podem ser diversas, como os motivos podem ser diversos. A entrevistada é enfática:

Eu preciso de uma pessoa que me cobre muito, que esteja ali comigo, e grite comigo, e fale comigo. Tipo assim, tenha pulso firme. Eu não gostaria de um personal que falasse manso. Falasse: “ah, tá bom, faz só dois". Não: “faz quinze, você tem capacidade!" Eu preciso de uma pessoa que me cobre mais. (E1).

Já outro entrevistado destaca: "Eu prefiro um (personal) mais tranquilo, que fala mais baixo, não fala muito, mais na dele. Porque para mim é um momento de relaxar. É o dia inteiro confusão na minha cabeça, aí chega aqui, ele me ouve, mais assim, meu psicólogo, do que ele fala” (E4).

Tratamos de motivação, mas ainda com o seu contraponto que é a desmotivação (motivação para não fazer, não adesão). A entrevistada assinala o que não lhe agrada: "Ela (a personal anterior) era muito devagar, deixava eu ficar muito parada, e eu já gosto de ficar parada, sou preguiçosa” (E3). Trata-se de um depoimento que remete para a necessidade de atenção redobrada com a pessoa que apresenta como característica a "preguiça". Uma "preguiça" que, no caso em tela, interpretamos relacionada à prática do exercício físico.

Os depoimentos acima nos remetem para a ideia de relação humana, portanto, para um trabalho que não se restringe à dimensão corporal física. Dito em outras palavras, parece importante que o personal trainer não olhe para o corpo do seu cliente e enxergue apenas um organismo. Considere-se assim, por exemplo: a necessidade de se fazer presente um personal que cobre o comportamento na prática; a condição relevante de o cliente estar ao lado de uma pessoa que ouve, que percebe encontrar-se diante de um corpo que tenta escapar da "confusão" do dia vivido; o valor de um profissional que compreende a "preguiça" e consegue fazer com que ela se transforme em ação, em movimento, se possível, prazeroso, estético.

Bossle e Fraga (2011) observam que a manutenção de relações contínuas de longo prazo com o cliente pode ser entendida como um objetivo do treinamento personalizado, sendo possível ainda considerar, no contrato firmado entre ambos, a ideia de gerenciamento da vida do cliente. Nesse sentido, a atuação do personal trainer extrapola o momento da prática do exercício físico, abarcando uma orientação mais abrangente, associada ao cotidiano da pessoa. Podem-se incluir, assim, recomendações relacionadas 
à gerência da rotina diária do cliente, por exemplo, dos seus hábitos alimentares, dos seus horários de sono, do seu vestuário.

Quanto à ideia de relações contínuas, estabelecidas entre profissionais (personal trainer) e clientes, verifica-se nos dados desta pesquisa uma média aproximada de 3 anos. Considerando as 12 entrevistas realizadas, o tempo mínimo informado é de um mês, e o máximo de 11 anos, como se pode verificar no Quadro 1.

De fato, motivar o cliente e favorecer a adesão ao trabalho será sempre um desafio para o personal, pois cada indivíduo tem razões diferentes para estar ali. Cabe então ao profissional visualizar de que forma irá proceder, para que as metas estabelecidas na interlocução entre ambos sejam alcançadas. Nesse sentido, a relação entre resultado esperado (planejado, objetivado) e resultado alcançado é determinante para a adesão ao trabalho do personal:

Eu tive uma melhora, assim, absurda, de dois meses para cá. Porque eu queria perder peso. E foi o que realmente eu consegui. Mesmo sem me pesar, eu vejo isso pelas minhas roupas e tal. Todos os objetivos estão sendo alcançados. Ele foca no que eu quero. (E6).

Como já sugerido acima, tendo por base Silva e Araújo Silva (2009), parece coerente compreender que alguns resultados podem ser obtidos de maneira mais satisfatória com o uso do treinamento personalizado, quando comparados aos derivados dos exercícios físicos realizados com a orientação que é em geral oferecida pelas academias. Com efeito, aquela em que o profissional que é momentaneamente responsável, por exemplo, pela "sala de musculação", disponibiliza-se a instruir as diferentes pessoas que ali se encontram.

Cite-se, também, no âmbito da discussão que buscamos empreender neste estudo, o cuidado que o personal trainer deve ter para não deixar transparecer sentimentos e emoções desagradáveis que possam influenciar o cliente. Percebe-se que o praticante prefere um profissional que demonstre animação e disposição durante a realização do seu trabalho:

As fichas dele são boas, ele é sempre animado. Nunca vi o (personal) desanimado; em dois anos. Então, ele está sempre para cima. Isso, querendo ou não, ajuda também. Porque se você pega um personal que não faz nada, que "ah, hoje eu estou desanimado também”, aí você já está com preguiça, o personal está com preguiça, aí: “ah, vamos bater papo, vamos fazer nada não”. (E3).

Em consonância com o que constata Coelho Filho (2005), interpretamos ser fundamental que o personal transmita energia durante as sessões de que orienta, porquanto o cansaço pode emergir como um dos elementos que mais vai interferir na qualidade do seu trabalho e, consequentemente, na avaliação do seu trabalho por parte do cliente. 
Outro elemento destacado é a flexibilidade. Os depoimentos nos mostram que uma característica valorizada no personal trainer é a de que ele se mostre flexível às necessidades e/ou dificuldades do cliente. Observemos o que é dito nos extratos: "Muda o dia, muda horário, repõe aula. Bem flexível” (E11).

O que eu acho de diferente nele, que os outros talvez não tenham, é a flexibilidade. Se eu ligar para ele e falar: "Fulano, eu não estou bem hoje, não estou em condições de malhar". Ele entende bem, ele aceita bem: "ah, a gente repõe essa aula". Com ele é muito mais tranquilo. (E6).

Importa assinalar, nesse ponto, que o personal training pode ser reconhecido como uma atividade em que o profissional de Educação Física atua como autônomo, gerenciando o próprio negócio (BOSSLE; FRAGA, 2011). Para Carmo Jr., Gobbi e Teixeira (2013), é na figura do personal trainer que o profissional de Educação Física desponta como um prestador de serviços, um “profissional-empreendedor” que, através de conhecimentos multidisciplinares, tem atuação voltada para a saúde. Portanto, com a imagem do personal gerenciando um negócio, ou prestando um serviço que implique em alternativas para atender aos interesses dos clientes, evocamos a "acumulação flexível" e sua peculiaridade de ser "marcada por um confronto direto com a rigidez do fordismo. Ela se apoia na flexibilidade dos processos de trabalho, dos mercados de trabalho, dos produtos e padrões de consumo" (HARVEY, 2008, p. 140).

Mas a interpretação nos permite também vislumbrar a contradição, pois se há valorização do profissional flexível, daquele que não demonstra contrariedade quando o cliente quer remarcar a sessão de treinamento, esse mesmo cliente que exige flexibilidade do outro parece desvelar uma postura que podemos associar à rigidez, ao apontar para a pontualidade agregando valor ao trabalho do personal: "Ah, ele é muito comprometido; por exemplo, não falha com horário, não atrasa. É muito correto. Então, assim, igual a mim; então casa direitinho" (E4). "Eu gosto muito dela e me identifico com ela bastante. Por isso estou até hoje com ela. Ela é pontual” (E5). "É pontual, é rigoroso, fica em cima, entendeu?” (E8).

Para Pinheiro (2000), o personal trainer deve possuir titulação, assiduidade, pontualidade, seriedade, cultura geral, capacidade de comunicação, atenção especial e comportamento social e profissional. Sublinhemos então as ideias de seriedade e atenção especial. Nesse diapasão, o uso do aparelho celular durante as sessões de treinamento merece ser considerado pelo personal trainer.

Os depoimentos apontam para certa desmotivação relacionada ao fato de o profissional fazer uso de celular durante a sessão de treinamento, bem como para o descarte de um profissional que é comumente observado fazendo uso do celular enquanto trabalha. O número de ocorrências é representativo e as falas são bastante enfáticas em relação a essa questão: "Eu acho assim, quando eu vejo os outros, a questão do celular" (E5). "Os outros eu via muito no celular, assim, batendo papo" (E7). "Tem personal que fica com celular na mão e te dando aula. Ele não, ele estava sempre ali, em cima, alongando e tal. Aí eu fui 
perguntando, aí eu cheguei nele; e gostei, e fiquei” (E8). “Acho péssimo. De vez em quando eu comento com elas: "olha lá fulano, dando aula e no celular"” (E9). "A aula é uma hora, e você tem que aproveitar essa hora. Têm pessoas, eu já observei, celular, e a pessoa fica batendo muito papo com o próprio aluno" (E11). "Eu percebo as pessoas, muito dispersas, muito desligadas, e talvez até com o celular ali dando personal" (E12).

Decerto, o profissional fazer uso do celular durante a sessão pode causar dispersão, quiçá constrangimento. Os depoimentos nos mostram a importância de que o personal esteja pleno durante o trabalho, dando atenção ao cliente. Trata-se, contudo, de uma constatação que não pode se estabelecer alienada ao advento das novas tecnologias no mundo contemporâneo. Conforme Bannister e Remenyi (2009), é indiscutível que as tecnologias móveis têm contribuído para mudar a forma como as pessoas trabalham e conduzem os seus dias. Um dispositivo móvel de comunicação proporciona alternativas na vida pessoal e profissional. A título de exemplo, há possibilidade de estar em contato permanente com uma rede de relacionamentos, de resolver situações corriqueiras a qualquer hora e lugar, de entreter-se "navegando" na internet.

Mas no bojo da discussão relacionada ao uso do celular, o "vício" deve ser considerado pelo personal, ou pelo candidato a atuar futuramente como personal trainer. Com efeito, o vício que contribui para que muitas pessoas passem um sexto do dia (três a quatro horas em média) interagindo com os celulares (DORIA, 2017). Para conferir se existe alguma notificação nova, sentem necessidade de sacar os seus telefones à toa, toda hora. Considere-se também o que apontam Oliveira et al. (2015) acerca da utilização do celular como ferramenta de trabalho, o que colabora para que a pessoa acabe recebendo mensagens e pedidos de informação até mesmo fora do horário de trabalho, gerando curiosidade e ansiedade, além da queda de produtividade.

Portanto, à constatação de que o uso do celular por parte do personal pode gerar problemas para a dinâmica qualitativa da sessão de treinamento, soma-se o alerta para o profissional de Educação Física que pretende investir no personal training, implícito no discurso dos entrevistados e expresso na seguinte questão: potenciais clientes podem ficar propensos a não contratar profissionais que usam (ficam ocupados com) aparelhos celulares durante as sessões de treinamento que orientam?

É possível constatar que motivos diversos estão associados à adesão ao trabalho do personal trainer. Mas acrescente-se ainda uma variável que nos parece merecedora de aprofundamento em futuras investigações. Trata-se do que aqui estamos interpretando como condição de heteronomia, demonstrada pelas pessoas entrevistadas. Heteronomia que aponta para dependência, submissão e obediência, mas também, importa aqui ressaltar, para a ideia de autonomia que lhe contrapõe. Autonomia que sugere 
liberdade e independência, faculdade de se reger por si mesmo (SIGNIFICADO... 2016). Com efeito, heteronomia e autonomia que nos remetem para a noção de "cuidado de si mesmo" (FOUCAULT, 2010, p. 4), em certo sentido, para "uma prática refletida sobre si mesmo e não uma obediência nua ao saber do outro (MENDES; GLEYCE, 2015, p. 513). Como ressalta Foucault (2010, p. 107), “os textos dos epicuristas e dos estoicos sobre o assunto são numerosos e iterativos: afinal, um escravo pode ser mais livre que um homem livre se este não tiver se liberado de todos os vícios, paixões, dependências, etc., em cujo interior estivesse preso".

Observemos os trechos: "Eu não conseguia ter a determinação de sair de casa para ir treinar, precisava de alguém que me ajudasse a ter esse ânimo extra" (E1). "Personal para mim é tudo. Assim, se eu parar de ter o personal acho que não venho mais" (E4). "Eu tenho ele hoje como prioridade. Quando eu vejo as pessoas malhando sozinhas, eu fico assim: 'nossa! Não conseguiria"” (E6). "Hoje eu não faço nada sem personal, não faria mais nada sem personal" (E9). "Eu fiquei uns dois meses sem, e eu tive muita dificuldade. Eu sou muito preguiçosa. Eu só quero agora malhar com personal" (E11).

\footnotetext{
Eu escolhi porque sozinha, às vezes, você fica com preguiça. Você vem, não está fazendo muito bem, está meio cansada, você acaba desistindo: "ah, amanhã eu faço". Isso desmotiva. Com o personal, ele está ali, você sabe que você tem que vir. Às vezes está cansada, aí fala: "ah, não, mas eu marquei com ele, ele está lá me esperando". (E7).
}

Bossle (2008) sugere que façamos um exercício de pensamento em que busquemos relacionar o trabalho do personal trainer com o do consultor privado dos primeiros séculos. $\mathrm{O}$ autor diz que existem diferenças cruciais entre estas duas figuras: o consultor privado objetivava o aconselhamento para assegurar a autonomia do indivíduo, enquanto o personal trainer parece visar à dependência eterna do cliente ao seu trabalho.

Decerto, lidamos com um problema que permite, inclusive, colocar em xeque a formação universitária em Educação Física e a intervenção profissional em Educação Física. E sendo a compreensão coerente, questões como as que aparecem a seguir nos soam pertinentes: os profissionais de Educação Física que atuam no campo do personal training já tiveram oportunidade de pensar sobre essa condição de dependência? Ela tendo sido pensada, não é criticada por ser comercialmente vantajosa para esse profissional? Como agente de ações vinculadas à educação e à saúde, qual papel tem assumido o profissional de Educação Física? Sendo profissionais da área, talvez devêssemos refletir mais profundamente sobre a nossa própria compreensão do que seja Educação Física? 


\section{Considerações finais}

Tendo em vista a análise e a interpretação dos dados empíricos coletados no presente estudo, destacamos as seguintes conclusões:

1) Os entrevistados enaltecem o trabalho do personal trainer por conta do apoio, do incentivo e do acompanhamento durante a execução dos exercícios. Nesse sentido, constata-se que há cobrança por um profissional que esteja sempre ao lado do cliente, que dê motivações para que ele faça as atividades com afinco. Contudo, deve-se considerar que o aspecto motivacional sempre imporá desafios ao personal, pois cada cliente tem as suas próprias motivações para estar ali praticando exercícios físicos sob sua orientação. Assim, o personal trainer deve ter sensibilidade para perceber as necessidades da pessoa que orienta, visualizando de que forma irá proceder, até mesmo para que as metas estabelecidas na interlocução entre ambos possam ser alcançadas.

2) O estudo nos leva a sublinhar a importância de que o personal trainer olhe (no sentido de avaliar, diagnosticar, perceber a pessoa) para o seu cliente e não enxergue apenas um organismo.

3) O personal trainer deve ter cuidado para não deixar transparecer sentimentos e emoções desagradáveis que possam influenciar (negativamente) a prática do exercício físico do seu cliente.

4) O profissional deve transmitir energia durante as sessões de treinamento que orienta, porquanto o cansaço pode se estabelecer como um dos elementos que vai interferir na avaliação da qualidade do seu trabalho.

5) O uso do celular por parte do personal emerge como elemento interveniente, podendo gerar problemas para a dinâmica qualitativa da sessão de treinamento orientada.

6) Duas características valorizadas, pelos entrevistados, em profissionais de Educação Física que atuam como personal trainer, são a flexibilidade para atender as necessidades de clientes (por exemplo, relacionadas à troca de horários) e a pontualidade.

Por fim, salientamos que ao longo desta pesquisa, pari passu ao frutificar de motivos relacionados à adesão ao trabalho do personal trainer, um em especial, não explicitado nos discursos, porém desvelado nas entrelinhas com a análise dos mesmos, despertou a nossa atenção. Foi a heteronomia demonstrada pelas pessoas entrevistadas. Trata-se do cliente que procura o personal trainer em busca de orientação para a prática do exercício físico e acaba encontrando uma condição de dependência do profissional. Sugere-se então a realização de estudos que elejam esta relação de dependência como objeto de análise, até mesmo para que, sem que percamos de vista as discussões associadas à ideia de emancipação sociocultural e ao 
tema da adesão à prática regular de atividades físico-esportivas, angariemos elementos que contribuam para que possamos pensar mais apropriadamente sobre a Educação Física como área de conhecimento e de intervenção profissional.

\section{Referências}

ALVES-MAZZOTTI, A. J. O planejamento de pesquisas qualitativas em educação. Cadernos de Pesquisa, São Paulo, v. 77, p. 53-61, mai. 1991.

ANVERSA A. L. B.; OLIVEIRA, A. A. B. Personal trainer: competências profissionais demandadas pelo mercado de trabalho. Pensar a Prática, Goiânia, v. 14, n. 3, p.1-17, set./dez. 2011.

BANNISTER, F.; REMENYI, D. Multitasking: the uncertain impact of technology on knowledge workers and managers. The Electronic Journal of Information Systems Evaluation, UK, v.12, n.1, p.1-12, 2009.

BOSSLE, C. B. O personal trainere o cuidado de si: uma perspectiva de mediação profissional. Movimento, Porto Alegre, v. 14, n. 1, p. 187-198, jan./abr. 2008.

BOSSLE, C. B.; FRAGA, A. B. O personal trainer na perspectiva do marketing. Revista Brasileira de Ciências do Esporte, Florianópolis, v. 33, n. 1, p. 149-162, jan./mar. 2011.

CARMO JR, W.; GOBBI, S.; TEIXEIRA, C. V. L. Personal trainer: a profissão, o profissional e a estrutura de um novo mercado. Pensar a Prática, Goiânia, v.16, n. 1, p. 248-266, jan./mar. 2013.

COELHO FILHO, C. A. A. Fruto maduro? Caindo do pé? In: TORRES, M.; SANTOS, R. F. (Orgs.). Lições de educação física 1. Rio de Janeiro, Univer Cidade Editora, 2005. p. 165-202.

COELHO FILHO, C. A. A. Narcisismo e sua relação com a prática de atividades físicoesportivas. Psicologia \& Sociedade, [S.1.], v. 26, n. 1, p.194-203, abr. 2014.

DORIA, P. Sim, teclas viciam. O Globo, Rio de Janeiro, 7 abr. 2017. Caderno Economia, p. 24.

FOUCAULT, M. A hermenêutica do sujeito. Tradução Márcio Alves da Fonseca, Salma Tannus Muchail. 3. ed. São Paulo: Martins Fontes, 2010.

HARVEY, D. Condição pós-moderna. Uma pesquisa sobre as origens da mudança cultural. Tradução Adail Ubirajara Sobral, Maria Stela Gonçalves. 17. ed. São Paulo: Loyola, 2008.

KAUFMANN, J-C. A entrevista compreensiva: um guia para pesquisa de campo. Tradução Thiago de Abreu e Lima Florencio. Petrópolis, RJ: Vozes; Maceió, AL: Edufal, 2013.

MENDES, M. I. B. S.; GLEYSE. J. O cuidado de si em Michel Foucault: reflexões para a Educação Física. Revista Movimento, Porto Alegre, v. 21, n. 2, p. 507-520, abr./jun. 2015.

OLIVEIRA, L. B. et al. Efeitos da tecnologia móvel sobre a qualidade de vida no trabalho. Revista Gestão \& Tecnologia, Pedro Leopoldo, v. 15, n. 2, p.161-185, mai./ago. 2015. 
PINHEIRO, D. R. V. O perfil do personal trainer na perspectiva de um treinamento físico orientado para saúde, estética e esporte. 178f. Dissertação (Mestrado em Ciência da Motricidade Humana), Universidade Castelo Branco, Rio de Janeiro, 2000.

PRADO, A. O. V.; LIBERAL, R. Motivos que levam mulheres a procurarem treinamento personalizado. Revista Brasileira de Prescrição e Fisiologia do Exercício, São Paulo, v. 2, n. 11, p. 564-577, set./out., 2008.

PRONI, M. W. Universidade, profissão Educação Física e o mercado de trabalho. Motriz, Rio Claro, v.16, n.3, p.788-798, jul./set., 2010.

SANCHES, E. W. Responsabilidade civil das academias de ginásticas e do personal trainer. São Paulo: Juarez de Oliveira, 2006.

SIGNIFICADO de Heteronomia. 2016. Significados. Disponível em: <https://www.significados.com.br/heteronomia/>. Acesso em: 31 ago. 2018.

SILVA, R. B.; ARAÚJO SILVA, E. A. A eficácia do controle do exercício físico através de um trabalho personalizado. Connection Line, Várzea Grande, n. 4, p. 27-36, 2009.

SOMBRIO, D. A. Motivos de adesão e aderência a prática de exercício físico do cliente/aluno de personal trainer no município de Criciúma- SC. 61f. Trabalho de Conclusão de Curso de Graduação (Bacharelado em Educação Física), Universidade do Extremo Sul Catarinense, Criciúma, 2011.

TERTULIANO, I. W.et al.Estrutura de prática e frequência de feedback extrínseco na aprendizagem de habilidades motoras. Revista Brasileira de Educação Física e Esporte, São Paulo, v. 22, n. 2, p.103-118, abr./jun., 2008.

Como citar este artigo

SILVA, J. N. P.; LIMA, L. C.; COELHO FILHO, C. A. A. Adesão ao trabalho do Personal Trainer. Revista Kinesis, Santa Maria, v. 38, p.01-14, 2020. 